\title{
Novel controlled and targeted releasing hydrogen sulfide system exerts combinational cerebral and myocardial protection after cardiac arrest
}

Xiaotian Sun ${ }^{*}{ }^{\circledR}$, Yiqing Wang ${ }^{\dagger}$, Shuyan Wen, Kai Huang, Jiechun Huang, Xianglin Chu, Fangrui Wang and Liewen Pang

\begin{abstract}
Background: Cardiac arrest (CA) is a leading cause of death worldwide. Even after successful cardiopulmonary resuscitation (CPR), the majorities of survivals are companied with permanent myocardial and cerebral injury. Hydrogen sulfide $\left(\mathrm{H}_{2} \mathrm{~S}\right)$ has been recognized as a novel gasotransmitter exerting multiple organ protection; however, the lacks of ideal $\mathrm{H}_{2} \mathrm{~S}$ donors which can controlled release $\mathrm{H}_{2} \mathrm{~S}$ to targeted organs such as heart and brain limits its application.

Results: This work utilized mesoporous iron oxide nanoparticle (MION) as the carriers of diallyl trisulfide (DATS), with polyethylene glycol (PEG) and lactoferrin (LF) modified to MIONs to acquire the prolonged circulation time and braintargeting effects, and a novel targeted $\mathrm{H}_{2} \mathrm{~S}$ releasing system was constructed (DATS@MION-PEG-LF), which exhibited excellent biocompatibility, controlled-releasing $\mathrm{H}_{2} \mathrm{~S}$ pattern, heart and brain targeting features, and the ability to be non-invasive traced by magnetic resonance imaging. DATS@MION-PEG-LF presented potent protective effects against cerebral and cardiac ischemic injury after CA in both in vitro hypoxia/reoxygenation models and in vivo CA/CPR models, which mainly involves anti-apoptosis, anti-inflammatory and anti-oxidant mechanisms. Accordingly, the cardiac and cerebral functions were obviously improved after CA/CPR, with potentially improved survival.
\end{abstract}

Conclusions: The present work provides a unique platform for targeted controlled release of $\mathrm{H}_{2} \mathrm{~S}$ based on MIONs, and offers a new method for combinational myocardial and cerebral protection from ischemic injury, bringing considerable benefits for CA patients.

Keywords: Cardiac arrest, Hydrogen sulfide, Mesoporous iron oxide nanoparticles, Ischemia and reperfusion injury, Combinational cerebral and myocardial protection

\section{Background}

Cardiac arrest (CA) claims around 450,000 lives per year in the United States, and only $10 \%$ of which can survive to hospital discharge [1, 2]. Even after successful cardiopulmonary resuscitation $(\mathrm{CPR})$ and return of spontaneous

*Correspondence: sunxiaotian@126.com

†Xiaotian Sun and Yiqing Wang contributed equally to this work Department of Cardiothoracic Surgery, Huashan Hospital of Fudan University, 12th Wulumuqi Rd, 200040 Shanghai, China circulation (ROSC) following CA, the majorities of survival patients are companied with multiple organ lesions $[1,3]$. Heart and brain are recognized as the two organs most sensitive to ischemic and reperfusion injury (I/R), and only $5 \sim 17 \%$ of survivors can avoid long term myocardial and cerebral injury [3]. Therapeutic hypothermia is the most applied treatment for post-resuscitation care after CA/CPR, however, it is also associated with severe adverse effects including hyperglycemia, arrhythmia, and infection [4]. Therefore, novel approaches for protecting

c) The Author(s) 2021. This article is licensed under a Creative Commons Attribution 4.0 International License, which permits use, sharing, adaptation, distribution and reproduction in any medium or format, as long as you give appropriate credit to the original author(s) and the source, provide a link to the Creative Commons licence, and indicate if changes were made. The images or other third party material in this article are included in the article's Creative Commons licence, unless indicated otherwise in a credit line to the material. If material is not included in the article's Creative Commons licence and your intended use is not permitted by statutory regulation or exceeds the permitted use, you will need to obtain permission directly from the copyright holder. To view a copy of this licence, visit http://creativecommons.org/licenses/by/4.0/. The Creative Commons Public Domain Dedication waiver (http://creativecommons.org/publicdomain/zero/1.0/) applies to the data made available in this article, unless otherwise stated in a credit line to the data. 
patients from myocardial and cerebral injuries after CA is still in highly demand.

Recently, hydrogen sulfide $\left(\mathrm{H}_{2} \mathrm{~S}\right)$ has been reported as a novel gasotransmitter that can exert various physiological effects, particularly in the cardiovascular system and center nervous system (CNS). Increasing evidences suggest that the administration of exogenous $\mathrm{H}_{2} \mathrm{~S}$ can successfully attenuate myocardial and cerebral $\mathrm{I} / \mathrm{R}$ injuries, involving various mechanisms including anti-inflammation, anti-apoptotic, and antioxidant $[5,6]$. However, the lack of ideal $\mathrm{H}_{2} \mathrm{~S}$ donors that can be targeted to heart and brain organs and controlled release $\mathrm{H}_{2} \mathrm{~S}$ largely limits the application of $\mathrm{H}_{2} \mathrm{~S}$ in combinational cerebral and myocardial protection. Sodium hydrosulphide (NaHS) is the most commonly used $\mathrm{H}_{2} \mathrm{~S}$ donor in animal experiments $[7,8]$, but the instant release of $\mathrm{H}_{2} \mathrm{~S}$ from NaHS cannot mimic the slow and continuous $\mathrm{H}_{2} \mathrm{~S}$ generation in the in vivo environment, which also leads to imprecise experimental results and detrimental effects [8,9]. Some slow releasing $\mathrm{H}_{2} \mathrm{~S}$ donors such as morpholin-4-ium 4-methoxyphenyl-morpholino-phosphinodithioate (GYY4137) can increase $\mathrm{H}_{2} \mathrm{~S}$ levels slowly, but their release processes are hardly to be regulated [9], and cannot be targeted to certain organs such as brain and heart, limiting the therapeutic efficiency in lesion organs. In the previous study, we have utilized the mesoporous silica nanoparticles (MSN) to load the $\mathrm{H}_{2} \mathrm{~S}$ donor diallyl trisulfide (DATS), and a GSH-triggered, slow releasing $\mathrm{H}_{2} \mathrm{~S}$ system has been constructed (DATS-MSN), which can slowly release $\mathrm{H}_{2} \mathrm{~S}$ in vitro and in vivo [10]. However, MSN cannot be utilized by mammal [11], leading to some biosafety concerns. Also, MSN cannot be traced by magnetic resonance (MRI), which is not suitable for a drug delivery system. Furthermore, MSN are easily adsorbed by plasma protein with limited circulation time, and not able to transport across blood-brain barrier (BBB), limiting the effects of its loading drugs in central nervous system (CNS).

Herein, we have constructed a novel $\mathrm{H}_{2} \mathrm{~S}$ releasing system utilizing mesoporous iron oxide nanoparticle (MION) as the carriers of DATS. Unlike MSN, MION could be fully metabolized and easily traced in vivo, and the hydroxyl surface of which also makes it easily modified with functional groups. Polyethylene glycol (PEG) was modified to MIONs to acquire the prolonged circulation time, and lactoferrin (LF) was introduced to help nanoparticles to across the BBB and gain brain-targeting effects. Then a biocompatible, trackable, heart and brain targeted, controlled-releasing $\mathrm{H}_{2} \mathrm{~S}$ system was developed (DATS@MION-PEG-LF) (Fig. 1). Biocompatibility, $\mathrm{H}_{2} \mathrm{~S}$ release pattern, organ targeting ability, and the myocardial and cerebral protective effects were investigated both in vitro and in vivo.

\section{Results}

\section{Characterization}

TEM images indicate that MIONs are monodisperse with uniform size and regular mesoporous (Fig. 2a, b).

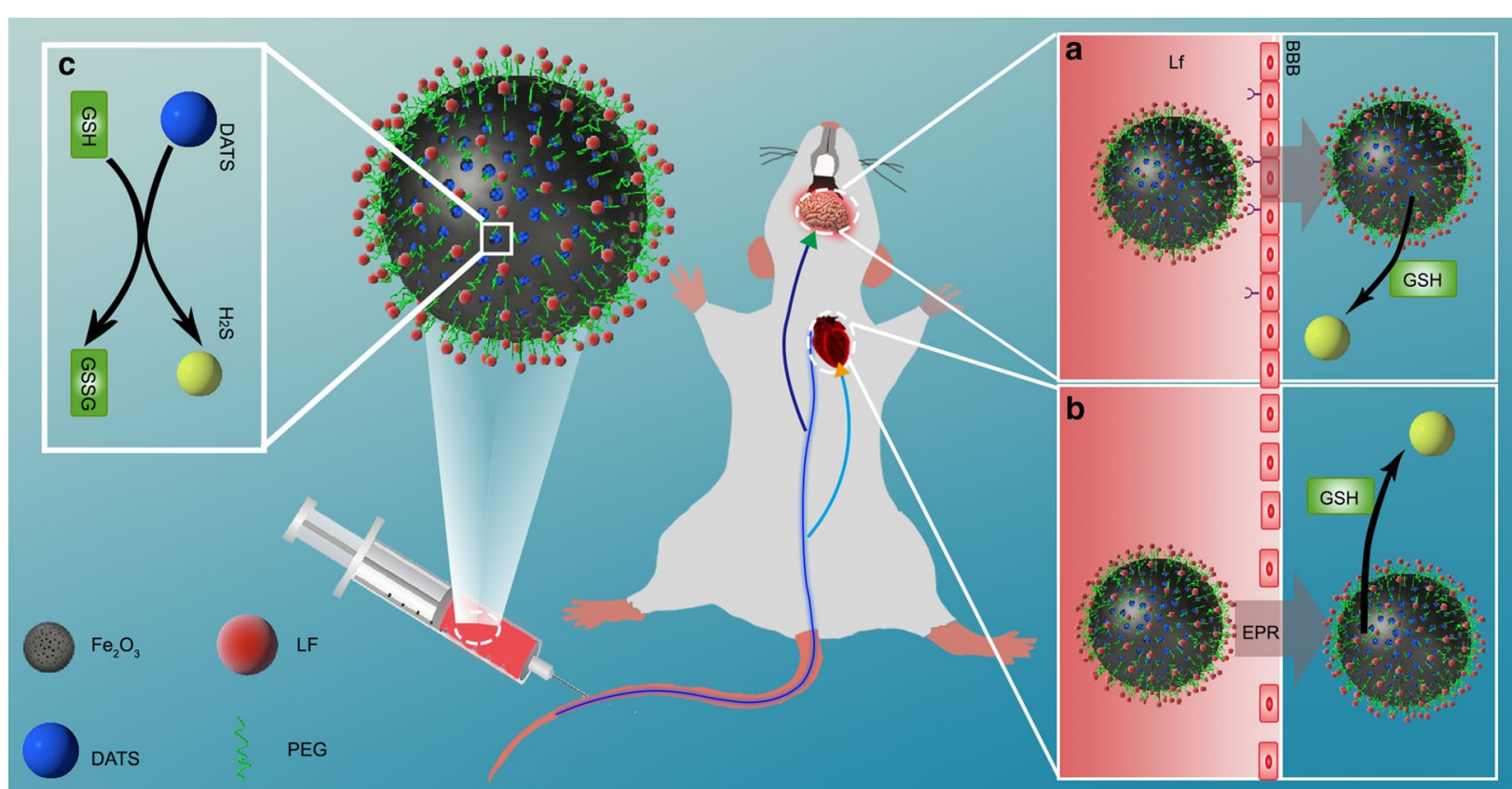

Fig. 1 The schematic of design and working principle of the novel $\mathrm{H}_{2} \mathrm{~S}$ targeted releasing system DATS@MION-PEG-LF 

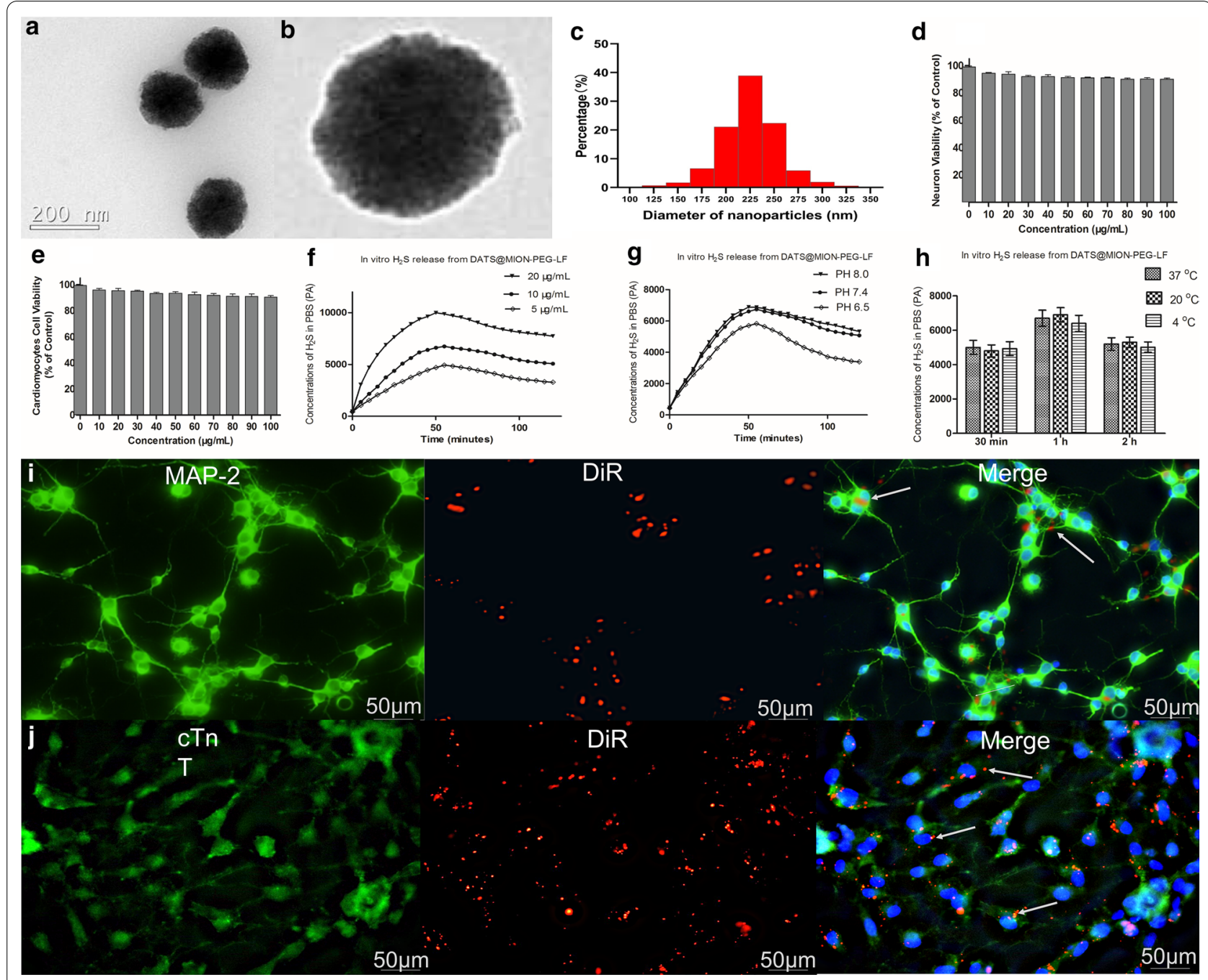

Fig. 2 Characterization, In vitro Cytotoxicity Assays, $\mathrm{H}_{2} \mathrm{~S}$ Release Assessment, and Cellular Uptake of DATS@MION-PEG-LF. a TEM and b enlarged TEM images. $\mathbf{c}$ The DLS results demonstrated a narrow size distribution of the nanoparticles. $\mathbf{d}$ Neuron and $\mathbf{e}$ cardiomyocytes cell viability after incubated for $24 \mathrm{~h}$ in different concentrations of DATS@MION-PEG-LF (mean \pm SEM, $\mathrm{n}=3$ ). f Release of $\mathrm{H}_{2} \mathrm{~S}$ from DATS@MION-PEG-LF in PBS solution. DATS@ MION-PEG-LF $(20,10$, and $5 \mu \mathrm{g} / \mathrm{mL})$ with GSH $(2 \mathrm{mM})\left(\mathrm{pH} 7.4,37^{\circ} \mathrm{C}\right) . \mathbf{g}$ DATS@MION-PEG-LF $(10 \mu \mathrm{g} / \mathrm{mL})$ with GSH $(2 \mathrm{mM})$ at pH 7.4, 6.5, and 8.0 (37

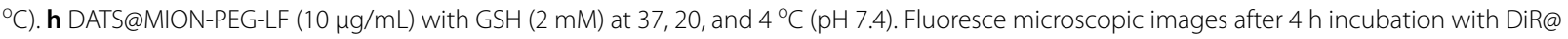
MION-PEG-LF $(50 \mathrm{\mu g} / \mathrm{mL}$ ) in neurons (i) and cardiomyocytes (j). Red: DiR@MION-PEG-LF, Green: cytoplasm stained by cTnT (cardiomyocytes) and MAP-2 (neurons), Blue: nucleus stained by DAPI

The nanoparticles had a narrow size distribution around $229 \pm 32 \mathrm{~nm}$ by DLS assay (Fig. 2c). The conjugation of Mal-PEG-NHS and LF to MIONs were confirmed by FT-IR spectroscopy (Additional file 1: Figure S2). According to the standard curve given by the ELISA kit, the average amounts of LF conjugated onto MION were around 82 per MION. After drug loading, the average weight of the DATS loaded nanoparticles was founded to be around 1.64 times that of free nanoparticles, calculating the drug loading efficiency of MION-PEG-LF equal to $39 \%$.

\section{In vitro cytotoxicity assays, $\mathrm{H}_{2} \mathrm{~S}$ Release Assessment} and cellular uptake

DATS@MION-PEG-LF showed no significant toxicity (cell viability $>90 \%$ ) at the concentration up to $100 \mu \mathrm{g} / \mathrm{mL}$ in both cardiomyocytes and neurons (Fig. 2d, e), suggesting that it can be safely used as $\mathrm{H}_{2} \mathrm{~S}$ donor in vitro in this range of concentrations.DATS@MION-PEG-LF released moderate amounts of $\mathrm{H}_{2} \mathrm{~S}$ in PBS steadily, which varied with the concentration DATS@MION-PEG-LF (Fig. 2f). The release of $\mathrm{H}_{2} \mathrm{~S}$ from DATS-MSN is $\mathrm{pH}$ dependent (Fig. 2g) as it is significantly inhibited in an acidic (pH 6.5) 
compared with neutral ( $\mathrm{pH}$ 7.4) environment, while alkaline PBS ( $\mathrm{pH}$ 8.0) did not apparently affect $\mathrm{H}_{2} \mathrm{~S}$ release. Temperatures $\left(37,20\right.$ and $4^{\circ} \mathrm{C}$ ) have negligible impacts on generation and release of $\mathrm{H}_{2} \mathrm{~S}$ (Fig. $2 \mathrm{~h}$ ). $\mathrm{H}_{2} \mathrm{~S}$ formation was observed at the beginning of the drug adding, and gradually increased over the first hour until reaching a plateau, indicating a steady and sustained $\mathrm{H}_{2} \mathrm{~S}$ release feature for DATS@MION-PEG-LF. Red fluorescence of DiR@MION-PEG-LF was observed in cytoplasm, proving that the nanoparticles are phagocytized by neurons and cardiomyocytes successfully (Fig. 2i, j). The fluorescent intensity of the nanoparticles is proportional to their number concentration, and a moderate concentration in cardiomyocytes was observed.

Protection effects of DATS@MION-PEG-LF against Hypoxia/ Reoxygenation induced damage of cardiomyocytes and neurons

In cardiomyocytes cell viability assay, obvious protective effects of DATS@MION-PEG-LF against hypoxic damage was observed at the concentrations among $0 \sim 10 \mu \mathrm{g} / \mathrm{mL}$, and the most effective concentration was around $5 \mu \mathrm{g} / \mathrm{mL}$ (Fig. 3a). The LDH evaluation showed similar results, which was significantly decreased by DATS@MION-PEG-LF administration (Fig. 3b). Meanwhile, DATS@MION-PEG-LF (5 $\mu \mathrm{g} /$ $\mathrm{mL}$ ) can significantly decrease the apoptosis proportion compared with the Control group by flow cytometry assay (Fig. 3c, d). In vitro neurons experiments showed similar results, with increased cell viability (Fig. 3e), decreased LDH levels (Fig. 3f), and reduced apoptosis proportion (Fig. $3 g, h$ ), and the most effective concentration was around $7 \mu \mathrm{g} / \mathrm{mL}$.

\section{Biodegradation and in vivo safety Assessment}

It has been reported that ferric oxide nanoparticles are mainly accumulated and metabolized in liver and spleen organs $[12,13]$. Accordingly, the present work studied the liver accumulation of DATS@MION-PEG-LF by MRI to present its biodegradation process: the hepatic fluorescence intensity reached its peak value around the 6th day after the injection, and then declined over the next 8 days, implying the gradual degradation and clearance of the nanoparticles (Fig. 4a, b). Meanwhile, the organ distribution assessment demonstrated that the brain and heart fluorescence intensities were elevated since $4 \mathrm{~h}$ after injection, and stayed increased within the $48 \mathrm{~h}$ experiments (Fig. $4 \mathrm{a}$, c, and d). H\&E staining at 2, 24 h, 7 and 30 days all revealed great biocompatibility of DATS@MION-PEG-LF: DATS@ MION-PEG-LF did not result in obvious damage to any vital organs after drug administration by H\&E (Fig. 4e). Meanwhile, compared with the Sham,DATS@MIONPEG-LF made no influence to either heart rates or mean artery pressure within $12 \mathrm{~h}$ (Fig. 4f, g), suggesting no obvious harm to hemodynamics. The Hematological and serological examinations at 2, $24 \mathrm{~h}$ and 7 days after injection of DATS@MION-PEG-LF also proved the in vivo biosafety of DATS@MION-PEG-LF (Additional file 1: Table S1). As shown in Fig. 4h, $\mathrm{H}_{2} \mathrm{~S}$ release from DATS@MION-PEG-LF in plasma is slow and stable, which obviously increased the plasma $\mathrm{H}_{2} \mathrm{~S}$ levels from the first time point, peaked at the 6th hour, and remained elevated over the $24 \mathrm{~h}$ experiments. The releasing of $\mathrm{H}_{2} \mathrm{~S}$ in plasma was also related to the dose of DATS@MION-PEG-LF administrated. The pharmacokinetic parameters of different doses DATS@MIONPEG-LF were described in Additional file 1: Table S2.

\section{In vivo targeting ability of DATS@MION-PEG-LF to Heart and brain}

Ex vivo imaging experiments presented that the DiR was successfully loaded into MION and MION-PEGLF to form DiR@MION and DiR@MION-PEG-LF, bearing the ability to represent the distributions of these nanocarriers in the in vivo experiments (Additional file 1: Figure S3). At $24 \mathrm{~h}$ after i.v injection of DiR@MION-PEG-LF, the brain tissue slices showed the obvious accumulation of DATS@MION-PEG-LF, which was mainly localized in neurons, this was not observed in the DiR@MION group (Fig. 5a), indicating the good targeting ability of DATS@MION-PEG-LF to brain via $L F$ modification. At the same time point, the heart tissue slices of DiR@ MION-PEG-LF and DiR@ MION groups both showed scattered DiR fluorescent signals dispersed in cardiomyocytes, indicating that the entrance of the nanoparticles to the heart tissues could be via the other mechanisms such as enhanced permeability and retention effect (EPR) effects (Fig. 5b). Accordingly, the $\mathrm{H}_{2} \mathrm{~S}$ content in tissues of the heart (Fig. 5c) and brain (Fig. 5d) were also elevated compared with the Vehicle group at 24 h after the DATS@ MION-PEG-LF administration, proving its delivery ability of $\mathrm{H}_{2} \mathrm{~S}$ to the heart and brain organs.

\section{DATS@MION-PEG-LF protects ischemic brain after CA/CPR}

As shown in Fig. 6a, DATS@MION-PEG-LF protected against brain apoptosis following $24 \mathrm{~h}$ of reperfusion. The apoptosis index was significantly decreased in the novel $\mathrm{H}_{2} \mathrm{~S}$ donor group compared with the Vehicle group (Fig. 6b). The rats receiving the novel $\mathrm{H}_{2} \mathrm{~S}$ donor also displayed a reduced degree of cerebral inflammation in comparison with the Vehicle group, with a reduction in MPO activities (Fig. 6c). DATS@MION-PEG-LF also resisted oxidative stress in brain tissues following the CA/CPR protocol, displaying an effective preservation of SOD activity (Fig. 6d) and CAT activity (Fig. 6e), and a reduced levels of MDA (Fig. 6f) compared with the Vehicle group. 


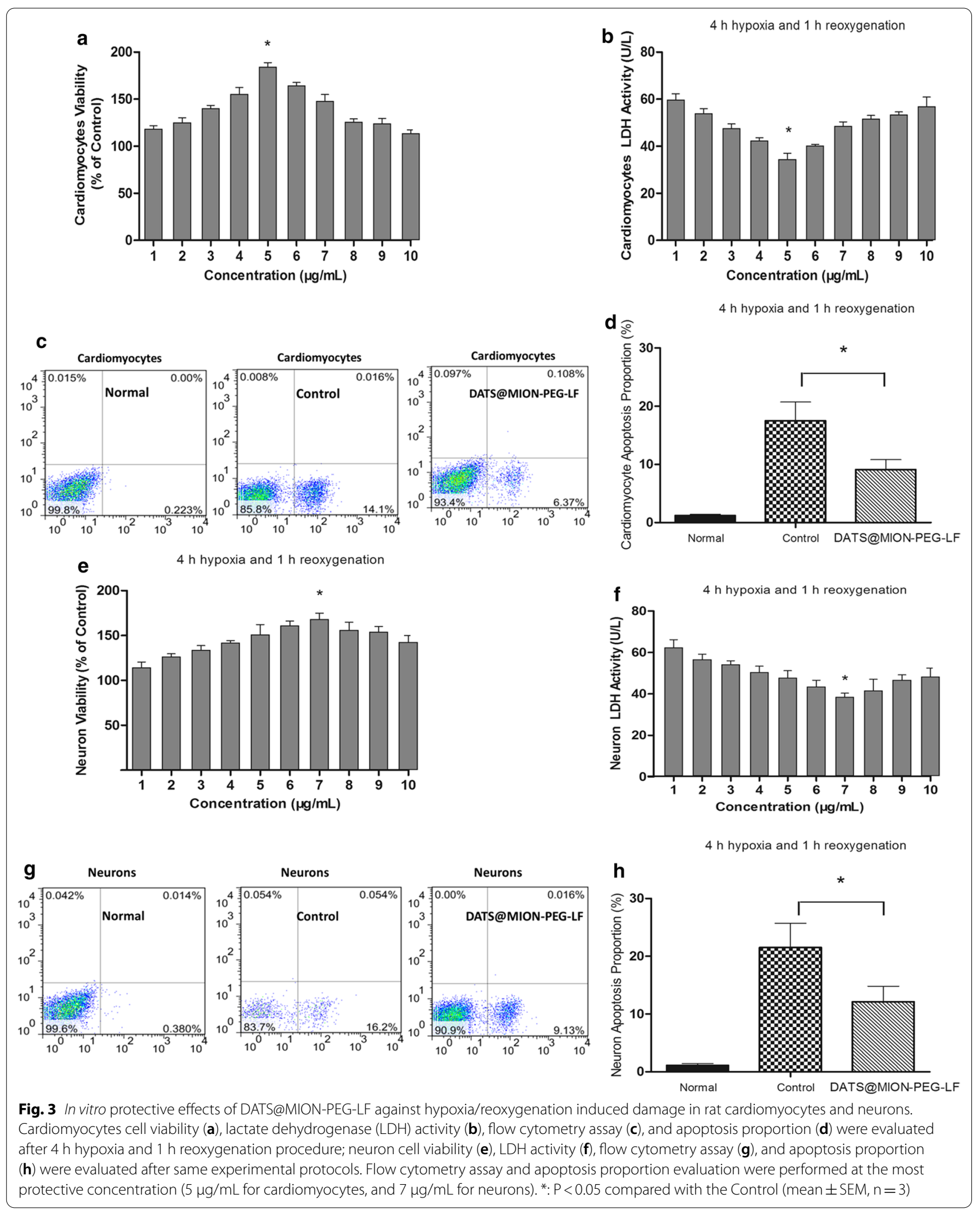


As shown in Fig. 6g-j, the I/R injury induced the expression of Caspase- 3 and BAX, and reduced the expression of Bcl-2 in the Vehicle group, and the DATS@MIONPEG-LF exhibited decreased levels of Caspase-3 and $\mathrm{BAX}$, and increased levels of Bcl-2, respectively.

\section{DATS@MION-PEG-LF protect ischemic myocardium after CA/CPR}

The protection effects of DATS@MION-PEG-LF to ischemic myocardium after CA/CPR protocol were similar to that of ischemic brain. By analyzing the ischemic myocardial tissue at $24 \mathrm{~h}$ after reperfusion, DATS@ MION-PEG-LF group showed significantly protection effects compared with Vehicle group, with obviously inhibited myocardial apoptosis (Fig. 7a, b), reduced myocardial neutrophil accumulation (Fig. 7c), resisted myocardial oxidative stress (Fig. 7d-f), and positive regulation of apoptosis related proteins (Fig. $7 \mathrm{~g}-\mathrm{j}$ ).

\section{DATS@MION-PEG-LF preserved cerebral and cardiac function after CA/CPR}

As shown in Fig. 8a, the survival rates had a tendency to be improved by DATS@MION-PEG-LF administration compared with the Vehicle. Correspondingly, the balance beam test scores and NDS scores were also obviously increased in the DATS@MION-PEG-LF group at 1 and 3 days after CA/CPR (Fig. 8b, c). Echocardiography results (Fig. 8d) revealed that DATS@MION-PEG-LF effectively preserved the cardiac function at 1 and 3 days after the CA/CPR, presenting an increased stroke volume (Fig. 8e), ejection fraction (Fig. 8f) and fractional shortening (Fig. 8g) when compared with the Vehicle group.

\section{Discussion}

The present treatment for early ischemic injury of heart and brain after CA is still in the challenge. As the main therapy strategy currently, therapeutic hypothermia causes increased risks of pneumonia and sepsis, and is far from sufficiency to improve the outcomes [14]. Therefore, it still calls for a convenient and efficient treatment method to combinational protect heart and brain organs, which can be easily applied at the early stage after CA. Bearing various physiology effects including antiinflammatory, anti-apoptosis and anti-oxidant effects of
$\mathrm{H}_{2} \mathrm{~S}$, a targeted and slow releasing $\mathrm{H}_{2} \mathrm{~S}$ system emerges as a promising tool for cerebral and myocardial protection from ischemic injury. The novel system presented good biocompatibility, controlled-releasing pattern, specific organ targeting ability, and combinational heart and brain protective effects.

MIONs were utilized as the framework of the new $\mathrm{H}_{2} \mathrm{~S}$ releasing system for many specific characteristics. Firstly, MIONs present superior biocompatibility with no obvious in vivo toxicity. Physiological iron can be found in various tissues in forms of hemosiderin, ferritin and transferrin, and MIONs could be transformed into ferritin or move into the intracellular storage iron pool with the similar homeostasis as physiological iron [15]. It has been widely reported that the MIONs were biodegraded mainly by liver, and excreted through urine and feces by the hepatobiliary process and urinary pathways; the eventual excretion could last for 21 days [15]. The present study demonstrated the superior biosafety of $\mathrm{MIONs}$ based $\mathrm{H}_{2} \mathrm{~S}$ releasing system both in in vitro and in vivo experiments, with excellent cell viability and no signs of organ damage. Secondly, bearing excellent superparamagnetism, MION enable itself to be traced non-invasively in vivo through MRI techniques, which is extremely important in pharmacokinetics and pathological diagnosis studies [16]. Our study utilized the traceable feature of MIONs to demonstrate its biodegradation process in vivo. Finally, the hydroxyls surface of MION endows itself the ability to be easily modified by various ligands [17], which was utilized to introduce PEG and LF in this study.

To guarantee the therapy efficiency, an ideal drug donor should bear a long circulation time with slowreleasing pattern. The diameter of MIONs is around $200 \mathrm{~nm}$, which could be slowly degraded and cleared by liver with relatively long circulation time [12]. Also, PEG modified MIONs could avoid the recognition by macrophages and removal by reticuloendothelial system, contributing prolonged duration in the plasma and increased organ uptake [18]. The slow-releasing mechanism of the novel $\mathrm{H}_{2} \mathrm{~S}$ donor involves DATS molecules gradually escaping from the mesopores of nanoparticles to slow down their reaction with GSH molecules and slowly generate $\mathrm{H}_{2} \mathrm{~S}$ [10]; the large surface area and pore volume of MIONs guaranteed this function.

\footnotetext{
(See figure on next page.)

Fig. 4 Biodegradation and In vivo Safety Assessment of DATS@MION-PEG-LF. a Coronal view of mouse by MRI scan, the hepatic, brain, and heart religion were selected for detecting fluorescence intensity (red circle).b Time course assessment of DATS@MION-PEG-LF intensity in mice by fluorescence intensity assessment, compared with the untreated mice (Normal).c Toxicity assessment of DATS@MION-PEG-LF via H\&E staining in vital organs. $\mathbf{d}$ Heart rates and e mean blood pressure in $12 \mathrm{~h}$ after injection. $\mathbf{f} \mathrm{H}_{2} \mathrm{~S}$ concentration in plasma after injection of DATS@MION-PEG-LF at different doses. (mean \pm SEM, $n=6$ )
} 


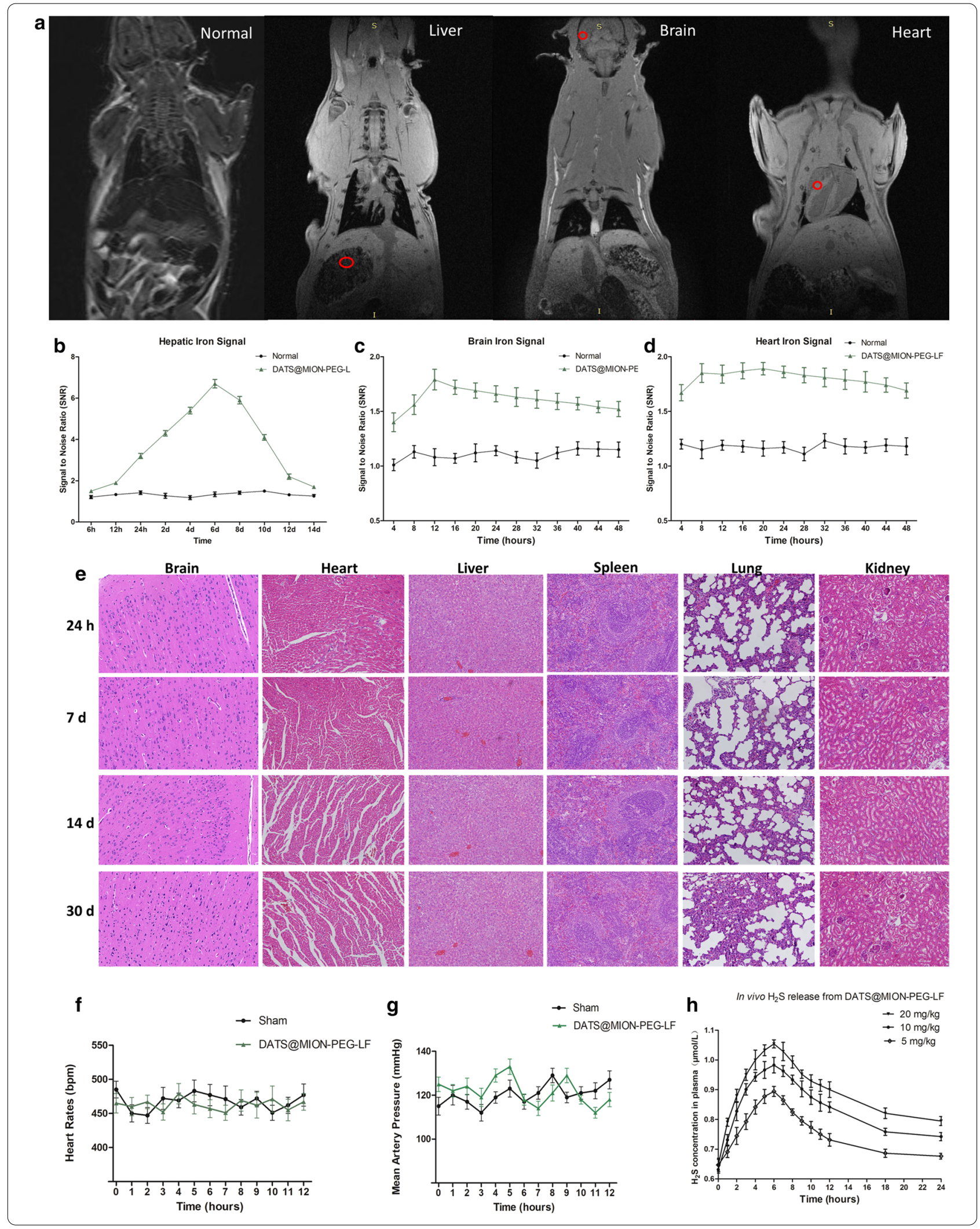




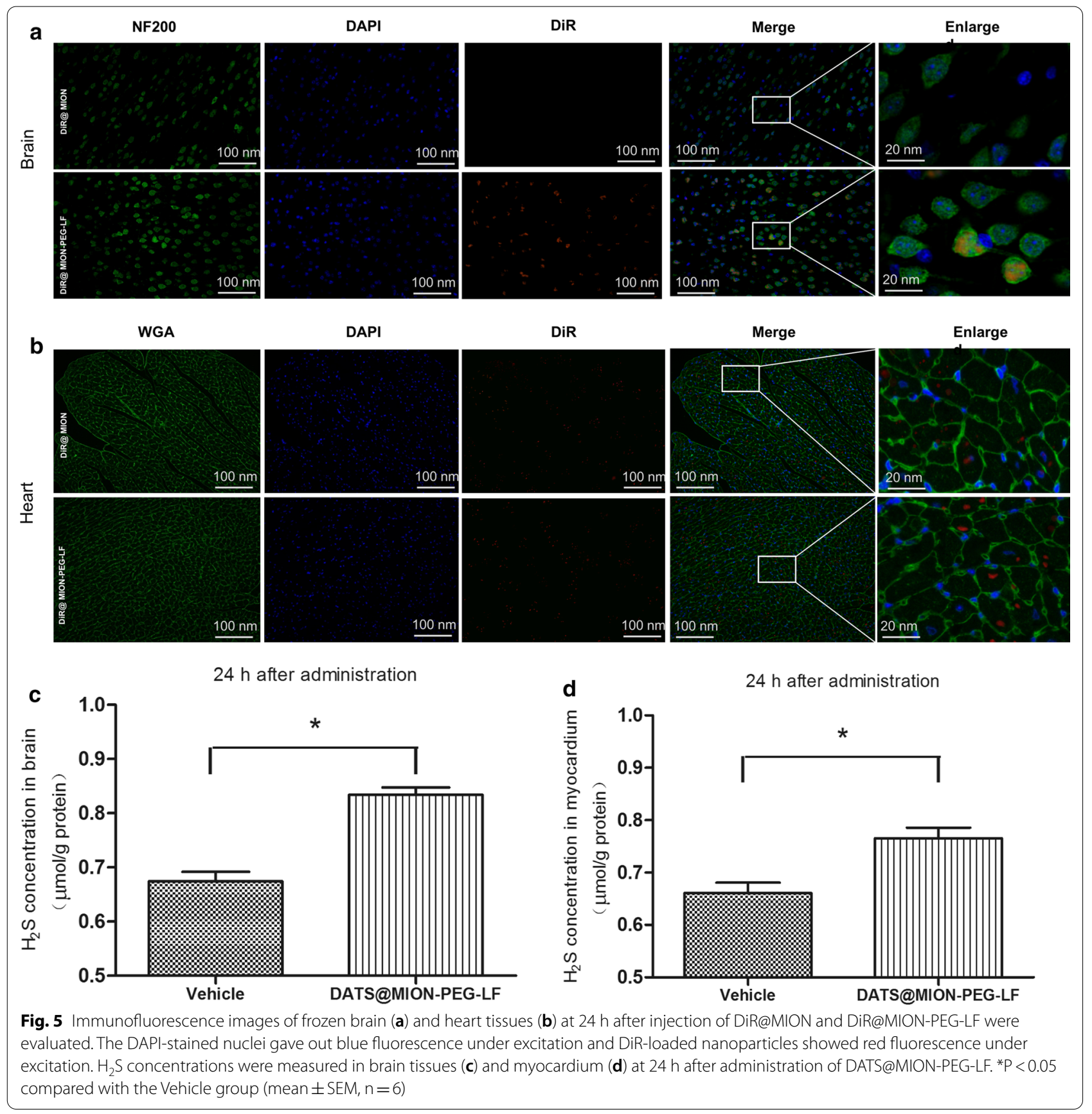

Therefore, the study provides a unique MION-based platform for long-term and controlled-release of $\mathrm{H}_{2} \mathrm{~S}$ in vitro and in vivo.

In order to achieve transportation ability to across BBB, brain-targeting ligand LF was modified to MIONs. Consisting of tightly connecting endothelial cells, the $\mathrm{BBB}$ is the most important shield of CNS, but also a great obstacle for drug targeting delivery in cerebral injury. To overcome this, many receptor-mediated drug delivery systems are developed recently by coupling of vectors with specific receptors on the BBB to drug loading vehicles. LF is a mammalian cationic iron-binding glycoprotein belonging to the transferrin family, and LF receptor is found on the $\mathrm{BBB}$ of different species and transports $\mathrm{LF}$ across the $\mathrm{BBB}$ in vitro and in vivo. Two classes of binding sites for LF were found on cell membrane: a high affinity $105 \mathrm{kDa}$ receptor protein and the low affinity glycosaminoglycans binding sites $[19,20]$. It is reported that 


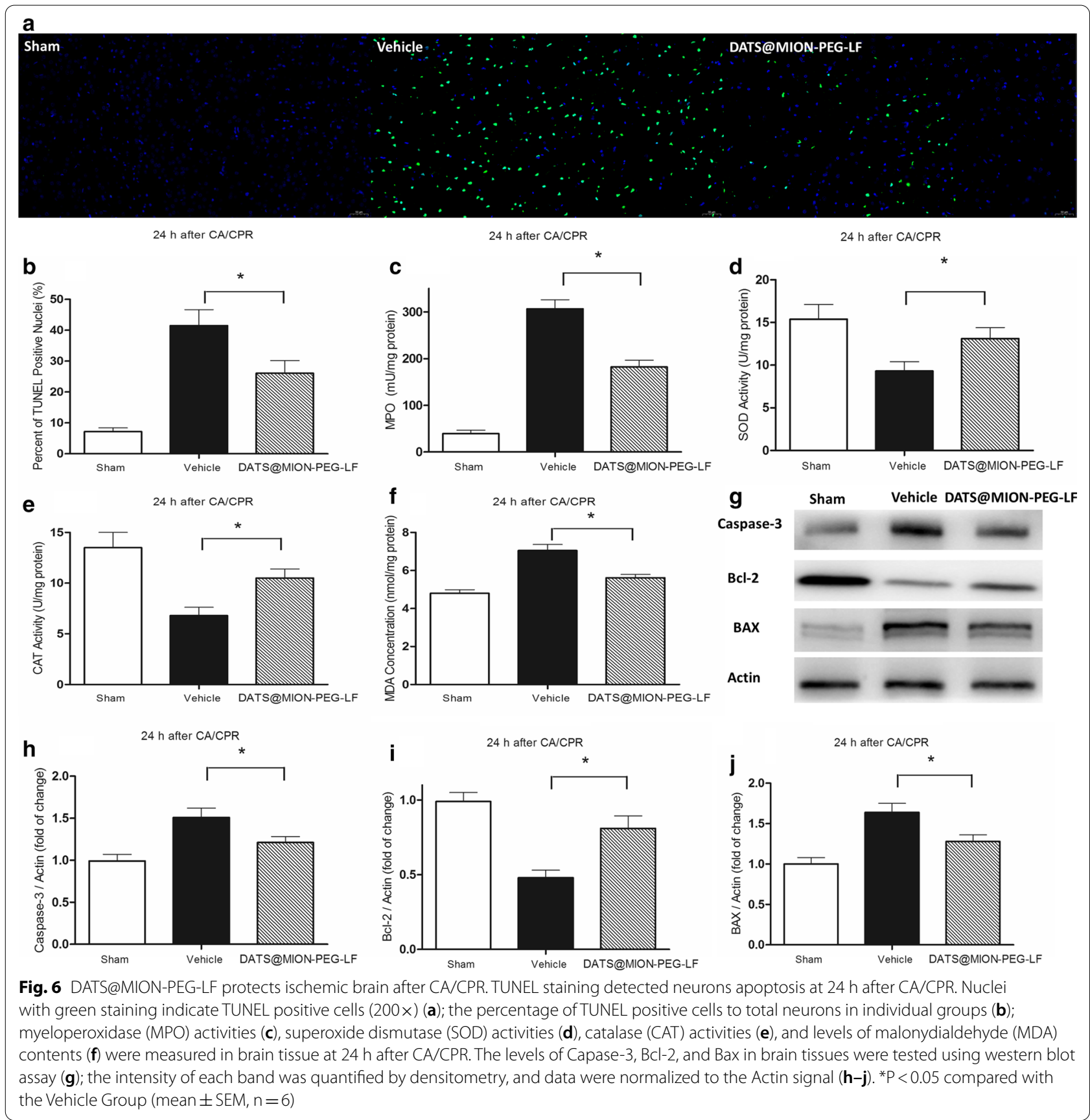

LF-modified DNA-loaded nanoparticles can transport across BBB through the receptor-mediated mechanism [19]. It is also reported that PEG-PLGA nanoparticles functionalized with LF can successfully appear in CNS [20]. Our study presented that only the LF-functionalized MIONs presented obvious fluorescent signals in brain, indicating adequate amounts of nanoparticles transported across into the brain tissues.
The uptake of modified MIONs by I/R myocardium is mainly depended on the enhanced permeability and retention (EPR) effects; in the myocardium undergoing $\mathrm{I} / \mathrm{R}$ damage, the microvascular permeability would be increased and permit more nanoparticles to across into the cardiomyocytes; the degree of microvascular injury and increased permeability correlate with the severity of ischemia [21]. In the myocardial infarction (MI) models, 


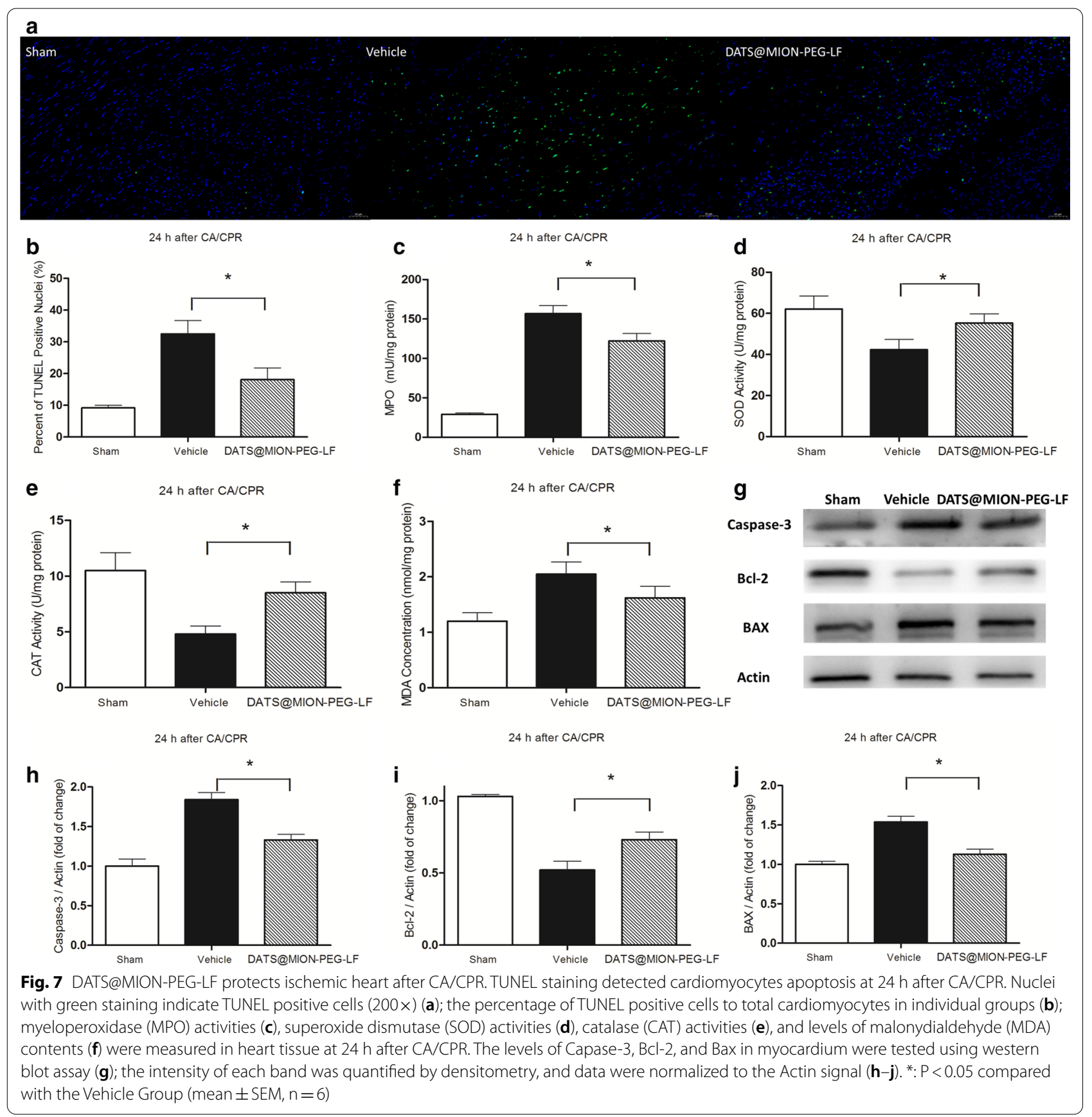

the nanoparticle accumulation following intravenous administration could be observed in the infarcted myocardium at the acute and chronic phase of MI, respectively [22]. In our CA/CPR model, the MIONs based $\mathrm{H}_{2} \mathrm{~S}$ releasing system was also successfully founded in ischemic myocardium.

As shown in this work, MIONs based drug delivery system present good biosafety in both in vitro and in vivo experiments. In the reported work, i.v. injection of LF connected nanoparticles may cause slight transient inflammatory reactions in the liver and spleen, but showed no obvious inflammatory reactions to other tissues such as brain and heart, with normal organ function and activities $[19,20]$. Our developed nanoparticles also demonstrated excellent biocompatibility in brain and heart up to $30 \mathrm{~d}$. However, further investigations should be concentrated on the long term toxicity on the important organs in vivo. 

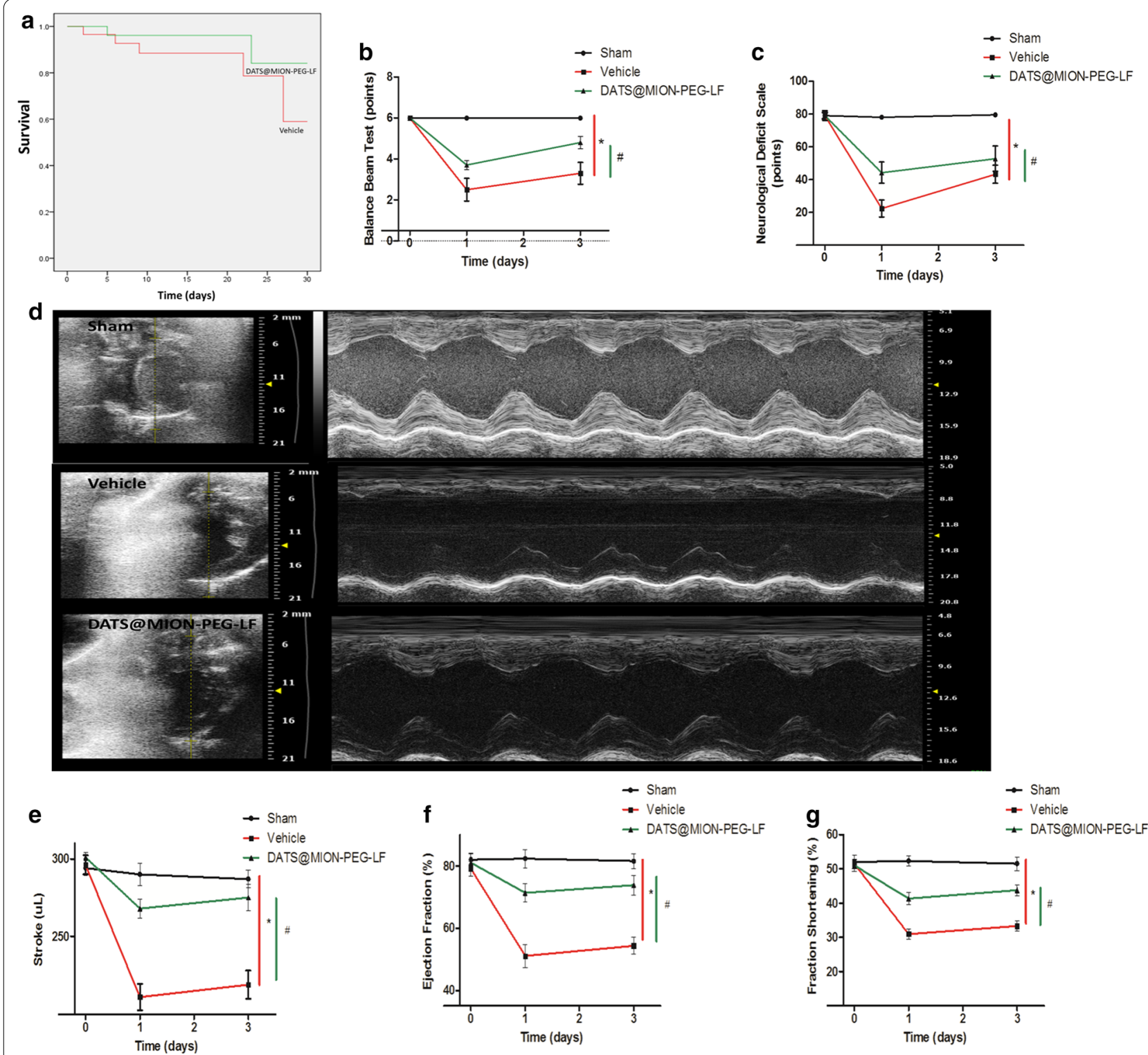

Fig. 8 Cardiac and cerebral function evaluation after CA/CPR. Survival estimates by Kaplan-Meier in Vehicle and DATS@MION-PEG-LF groups within $30 \mathrm{~d}$ after CA/CPR $(n=30)(\mathbf{a})$; balance beam test scores $(\mathbf{b})$ and neurological deficit scale scores (Emulsifying activity $\left(\mathrm{OD}_{500}\right)$ and emulsion index IE24c) in Sham, Vehicle and DATS@MION-PEG-LF groups at 1 and 3 days after CA/CPR; representative M-mode images from individual groups evaluated at 3 days after CA/CPR (d); stroke volume (e), ejection fraction (f), and fractional shortening $(\mathbf{g})$ measured by M-mode echocardiography at $1 \mathrm{~d}$ and $3 \mathrm{~d}$ after CA/CPR. ${ }^{*} \mathrm{P}<0.05$ compared between the Sham and the Vehicle Groups; \#P $<0.05$ compared between the DATS@MION-PEG-LF and the Vehicle Groups (mean $\pm S E M, n=6$ )

The accumulation of DATS@MION-PEG-LF in heart and brain is accompanied with elevated $\mathrm{H}_{2} \mathrm{~S}$ content in related organs. For those previous $\mathrm{H}_{2} \mathrm{~S}$ donors, the physiological effects of $\mathrm{H}_{2} \mathrm{~S}$ is mainly depended on the plasma $\mathrm{H}_{2} \mathrm{~S}$ supply. For $\mathrm{H}_{2} \mathrm{~S}$ is easily transferred across respiratory membranes, the residence time in tissues is relatively short for fast-releasing $\mathrm{H}_{2} \mathrm{~S}$ donors, somewhat limiting the biofunction effects of $\mathrm{H}_{2} \mathrm{~S}$ in organs.
A Nano-system which can be transported and stayed in the targeted organs could offer an accumulating $\mathrm{H}_{2} \mathrm{~S}$ circumstance over a long period, and provide superior therapeutic functions. With considerable uptake by neurons and cardiomyocytes, DATS@MION-PEG-LF can exert superior corresponding physiological effects of $\mathrm{H}_{2} \mathrm{~S}$. As to the present study, DATS@MION-PEGLF combinational protected ischemic brain and heart 
mainly via anti-apoptosis, anti-inflammatory, and antioxidant mechanisms. Many studies have reported that $\mathrm{H}_{2} \mathrm{~S}$ can exert anti-apoptotic effects via the inactivation of caspases caused by I/R [23]. In the presented study, DATS@MION-PEG-LF administration was associated with $\mathrm{H}_{2} \mathrm{~S}$-mediated modulation through increasing the levels of $\mathrm{Bcl}-2$, decreasing the levels of $\mathrm{BAX}$, and reducing the activity of caspases-3. Accordingly, the cerebral and cardiac functions were obviously improved after CA/ CPR, with potentially improved survival. Therefore, the present study provides a practical and safe way of $\mathrm{H}_{2} \mathrm{~S}$ treatment in ischemic organs, and offers a new insight into combinational organ protection of a MION based targeted releasing $\mathrm{H}_{2} \mathrm{~S}$ system.

\section{Conclusions}

The present study reported a multiple organ targeted $\mathrm{H}_{2} \mathrm{~S}$ releasing system based on MIONs, which exhibited good biocompatibility, controlled-releasing pattern, heart and brain targeting features, and ability to be non-invasive traced by MRI. DATS@MION-PEG-LF can present potent protective effects against cerebral and cardiac ischemic injury after $\mathrm{CA}$ in both in vitro cardiomyocytes and neuron hypoxia/reoxygenation models and in vivo $\mathrm{CA} / \mathrm{CPR}$ models. It provides a unique safe platform for controlled release of $\mathrm{H}_{2} \mathrm{~S}$ based on MIONs, and offers a new method for combinational myocardial and cerebral protection from I/R injury, bringing considerable benefits for CA patients.

\section{Materials and methods Materials and reagents}

Newborn (6 g, $24 \mathrm{~h}$ ) and adult male Sprague-Dawley rats (250-280 g, $8 \mathrm{w})$, as well as BALB/c-nu mice (15 g, $4 \mathrm{w})$ were used in this study. All animal experiments were approved by Institutional Animal Care and Use Committee of Department of Laboratory Animal Science of Fudan University (Grant No. 20160780A176), and confirmed with the Guide for the Care and Use of Laboratory Animals published by the US National Institutes of Health (NIH publication no. 85-23, revised 1996). DATS, 3-aminopropyltriethoxysilane (APTES), LF, N-succinimidyl-S-acetylthioacetate (SATA), and MalPEG-NHS were obtained from Sigma-Aldrich (St Louis, $\mathrm{MO})$. Other reagents were of analytical grade and used as purchased. All the solutions were prepared by Milli-Q water and deaerated with high-purity nitrogen.

\section{Preparation of MIONs}

The synthesis of MIONs followed our previously described protocol with minor modifications [24]. Briefly, styrene $(9 \mathrm{~mL})$, methacrylic acid $(1 \mathrm{~mL})$, and deionized water $(70 \mathrm{~mL})$ were mixed and dispersed. The suspension was then stirred and heated to $75{ }^{\circ} \mathrm{C}$ for $30 \mathrm{~min}$. Then $10 \mathrm{~mL}$ of potassium peroxodisulfate $(10 \mathrm{mg} / \mathrm{mL})$ was gradually added and react for $24 \mathrm{~h}$ at $75^{\circ} \mathrm{C}$. The obtained polystyrene nanoparticles were mixed with $30 \mathrm{~mL}$ of ethylene glycol and $170 \mathrm{~mL}$ of deionized water. After that, $450 \mathrm{mg}$ of ferrous chloride, $110 \mathrm{mg}$ of potassium nitrate, and $2 \mathrm{~g}$ of methenamine were sequentially added and heated to $80{ }^{\circ} \mathrm{C}$ under nitrogen protection. After cooling and centrifuging, collected nanoparticles were washed with distilled water to remove residual reagents, and gradually heated to $500{ }^{\circ} \mathrm{C}$ for $3 \mathrm{~h}$. After cooling to room temperature, MIONs were obtained.

\section{Synthesis of DATS@MION-PEG-LF}

The surface modifications of MIONs consist of conjugating Mal-PEG-NHS with MION and conjugating LF with Mal-PEG-MION (Additional file 1: Figure S1). Firstly, $5 \mathrm{~mL}$ of APTES was hydrolyzed under catalyzation of $\mathrm{HCl}(\mathrm{pH} 4.0)$ to form silane polymer with reactive saline bond, then $30 \mathrm{~mL}$ of deionized (DI) water and $10 \mathrm{mg}$ of MIONs were added. The mixture was stirred for $4 \mathrm{~h}$ at $65{ }^{\circ} \mathrm{C}$ under nitrogen protection, and was eluted with ethanol and DI water. Then $20 \mathrm{mg}$ of Mal-PEG-NHS (Mw: 5000) was added to the silane coated MIONs, and the mixture was allowed to react for $5 \mathrm{~h}$ at room temperature after $30 \mathrm{~min}$ nitrogen bubbling, following dialysis against DI water.

LF was activated before conjugated to Mal-PEG-MION according to previous method [25]. Briefly, LF and SATA were incubated in Hepes buffered saline $(\mathrm{pH} 7.0)$ at 1:8 molar ratios for $1 \mathrm{~h}$ at room temperature under constant shaking. Free SATA was removed by centrifugal ultrafiltration with the help of Millipore UFC801096 tubes $\left(12,000 \mathrm{rpm}, 30 \mathrm{~min}\right.$ at $\left.4{ }^{\circ} \mathrm{C}\right)$. SATA modified LF was reacted with $0.1 \mathrm{M}$ hydroxylamine for $45 \mathrm{~min}$ at room temperature before coupling to maleimide then was incubated with Mal-PEG-MION for $2 \mathrm{~h}$ at room temperature. After incubation, MION-PEG-LF went through centrifugal ultrafiltration with a $30 \mathrm{Kd}$ cut-off tube to dislodge uncombined LF and other impurities. After that, MIONPEG-LF solutions underwent FT-IR spectroscopy assay to confirm the conjugation of Mal-PEG-NHS and LF to MIONs (Perkin Elmer Frontier FT-IR, spectra recorded from wavenumber 400-4000 $\mathrm{cm}^{-1}$ ) (detailed in Additional file 1). The average amounts of LF conjugated to MION was estimated by enzyme linked immunosorbent assay (ELISA) kit method.

DATS was loaded into MION-PEG-LF based on the previous reported protocols $[8,10]$. In brief, $1 \mathrm{mg}$ of MION-PEG-LF and $1 \mathrm{mg}$ of DATS were sequentially mixed in $5 \mathrm{~mL}$ of distilled water, followed by stirring for $9 \mathrm{~h}$. Resident DATS were removed from the surface of MIONs by being washed with distilled water. Parts of 
cleaned DATS@MION-PEG-LF were freeze-dried under vacuum and weighed to count the loading efficiency of DATS (mass of drug loaded in nanoparticles/ mass of drug loaded nanoparticles $\times 100 \%$ ). Other parts of DATS@MION-PEG-LF were reserved in saline solutions at room temperature ready for use.

\section{Characterization}

The structure of DATS@MION-PEG-LF was analyzed by high-resolution transmission electron microscopy (HRTEM) images which were recorded by a JEM-2100F (JEOL, Japan) and a Tecnai T20 (FEI, USA) transmission electron microscope (TEM). The diameters of samples were acquired by averaging size of 50 nanoparticles in TEM images. Dynamic light scattering (DLS) Autosizer 4700 (Malvern, MA, UK) was used to measure the size distribution. The conjugations of Mal-PEG-NHS/LF to MIONs were confirmed by FT-IR method (Additional file 1). The samples were tested at $25{ }^{\circ} \mathrm{C}$ with concentration of $5 \mu \mathrm{g} / \mathrm{mL}$.

\section{Cytotoxicity assays of DATS@MION-PEG-LF}

Cytotoxicity assay of DATS@MION-PEG-LF was assessed using primary neonatal cardiomyocytes and neurons according to the previously described method $[10,26]$. The culture of cardiomyocytes and neurons were described in Additional file 1. The DATS@MION-PEGLF was diluted with culture medium to gain a concentration range from 0 to $100 \mu \mathrm{g} / \mathrm{mL}$, and was added to 96-well flat-bottomed tissue-culture plate with cell seeded. After incubation for $24 \mathrm{~h}$, medium was removed, and cells were washed with PBS, then the medium was replaced with cell counting kit-8 (CCK-8) solution (Dojindo Laboratories, Kumamoto, Japan). The absorbance of individual wells was measured at $450 \mathrm{~nm}$ by a microplate reader (Molecular Devices, FlexStation 3, CA, USA). The results were expressed as the mean percentage of cell viability relative to control.

\section{In vitro cellular uptake}

Fluorescent dye DiR was loaded to the MION-PEG-LF frameworks. The protocols of loading and the identification of DiR@MION-PEG-LF were described in Additional file 1 . Neonatal rat cardiomyocytes and neurons were treated with the DiR@MION-PEG-LF $(50 \mu \mathrm{g} / \mathrm{mL})$ in 24-well plates for $4 \mathrm{~h}$. After washed with PBS for thrice, the cells were fixed by $4 \%$ paraformaldehyde for $15 \mathrm{~min}$, penetrated by $0.1 \%$ triton-X 100 for $20 \mathrm{~min}$, stained by $\mathrm{cTnT}$ (cardiomyocytes) and MAP-2 (neuron) for $8 \mathrm{~h}$ and 4', 6-diamidino-2-phenylindole (DAPI) for $15 \mathrm{~min}$. Then the DiR@MION-PEG-LF $(\lambda \mathrm{ex}=750 \mathrm{~nm})$ inside cells were visualized using a fluoresce microscope (Olympus IX-71, Japan).

\section{In vitro $\mathrm{H}_{2} \mathrm{~S}$ release of DATS@MION-PEG-LF}

The in vitro release course of DATS@MION-PEG-LF was assessed by real time $\mathrm{H}_{2} \mathrm{~S}$-selective microelectrode assay: 5,10 , and $20 \mu \mathrm{g} / \mathrm{mL}$ of DATS@MION-PEG-LF was separately added to a glass chamber (World Precision Instruments, WPI, USA) containing PBS $(100 \mathrm{mM}, \mathrm{pH}$ 7.4, $4 \mathrm{~mL}$ ) with $2 \mathrm{mM}$ of $\mathrm{GSH}$ at $37^{\circ} \mathrm{C}$. Then $\mathrm{H}_{2} \mathrm{~S}$ formation was detected using ISO- $\mathrm{H}_{2} \mathrm{~S}-2$ sensor attached to an Apollo 1100 Free Radical Analyser (WPI, FL, USA). $\mathrm{H}_{2} \mathrm{~S}$ release was real-time displayed by picoamps (PA) current curve for $120 \mathrm{~min}$. DATS@MION-PEG-LF $(10 \mu \mathrm{g} / \mathrm{mL})$ with GSH $(2 \mathrm{mM})$ at $\mathrm{pH}$ of $7.4,6.5$, and $8.0\left(37^{\circ} \mathrm{C}\right)$, and DATS@MION-PEG-LF $(10 \mu \mathrm{g} / \mathrm{mL})$ with GSH $(2 \mathrm{mM})$ at 37,20 , and $4{ }^{\circ} \mathrm{C}$ (pH of 7.4) were also evaluated for $\mathrm{H}_{2} \mathrm{~S}$ release.

\section{Protection effects of DATS@MION-PEG-LF from hypoxia induced damage in rat cardiomyocytes and neurons} DATS@MION-PEG-LF $(1 \sim 10 \mu \mathrm{g} / \mathrm{mL})+$ GSH $(2 \mathrm{mM})$ and saline of same volume (Control) were separately added to medium of cultured cardiomyocytes or neurons $(\mathrm{n}=3)$. After incubation for $4 \mathrm{~h}$, medium was removed and replaced with DMEM/F-12 without glucose and serum. Then cardiomyocytes/neurons were exposed to hypoxia $\left(94 \% \mathrm{~N}_{2}, 5 \% \mathrm{CO}_{2}, 1 \% \mathrm{O}_{2}\right)$ for $4 \mathrm{~h}$ in a $\mathrm{CO}_{2}$ incubator (Forma SERIES II WATER JACKET, Thermo Scientific, MA, USA), followed by reoxygenation $\left(5 \% \mathrm{CO}_{2}\right)$ for $1 \mathrm{~h}$. After which, the cell viability was evaluated by CCK-8 assay and compared with the Control.

After the hypoxia/reoxygenation procedure, lactate dehydrogenase (LDH) activities of each group were also measured to evaluate cytotoxicity using an assay kit (JianCheng, Nanjing, China) according to the manufacturer's instructions. The absorbance was determined by a micro plate reader at $440 \mathrm{~nm}$. The levels of cell apoptosis were also determined by flow cytometry by previous method [27].

\section{Biodegradation and biodistributon assessment of DATS@ MION-PEG-LF}

Like almost all nanoparticles, intravenously administered MIONs are eventually cleared by mononuclear phagocytic system such as liver [28]. To investigate the in vivo metabolism and biodegradation of DATS@MION-PEGLF, BALB/c-nu mice ( $15 \mathrm{~g}, 4 \mathrm{w}, \mathrm{n}=6)$ were injected via the tail vein with $10 \mathrm{mg} / \mathrm{kg}$ of the DATS@MION-PEG-LF nanoparticles. Six mice were injected with same volume of saline and underwent same procedures as control. In vivo MRI scan was performed on 3-T MRI scanner (Discovery MRI 750, GE Medical Systems, Milwaukee, WI, USA) with an animal 8-channel phased-array coil with the following parameters: FSE T2 Fat Suppress, slice thickness: $1.0 \mathrm{~mm}$, spacing: $0.1 \mathrm{~mm}$, TR: $4167.0 \mathrm{~ms}$, TE: 
$68.0 \mathrm{~ms}$, refocus flip angle: $142^{\circ}$, echo train length: 24 , and bandwidth: $31.25 \mathrm{kHz}$. T2-weighted MRI was used to detect the aggregation of nanoparticles in mouse livers by evaluating the calculated signal intensity. The signal intensities of nanoparticles at $6,12,24$ h, 2, 4, 6, 8, 10, 12, and 14 days after injection were obtained in a region of interest (liver region) placed at the fixed site on matched slices. Signal to noise ratio (SNR) were calculated to compare the relative signal intensity. Repeat the protocols, and the SNRs of iron nanoparticles in mouse brains and hearts were evaluated within $48 \mathrm{~h}$ to assess the biodistribution of nanoparticles in brain and heart.

\section{In vivo toxicity assessment of DATS@MION-PEG-LF}

Sprague-Dawley rats were injected with DATS@MIONPEG-LF $(10 \mathrm{mg} / \mathrm{kg})$ through tail vein $(\mathrm{n}=6)$. Rats were euthanized at $24 \mathrm{~h}, 7,14$, and 30 days after injection, and brain, heart, liver, spleen, lung and kidney organs were harvested and fixed in $4 \%$ paraformaldehyde for $24 \mathrm{~h}$ at room temperature then embedded in paraffin and cut into $7 \mu \mathrm{m}$-thick slices. The sections were stained with $\mathrm{H} \& \mathrm{E}$ and imaged under a light microscope at $\times 40 \mathrm{mag}$ nification. Six high-power fields were randomly selected in each photograph. Hematological and serological examinations at $24 \mathrm{~h}, 7$, and 30 days after injections of DATS@MION-PEG-LF $(10 \mathrm{mg} / \mathrm{kg})$ or same volume of saline (Control) were also evaluated (Additional file 1).

\section{Effect of DATS@MION-PEG-LF on heart rates and blood pressure}

Sprague-Dawley rats $(n=6)$ were anesthetized with medetomidine hydrochloride (Domitor, $250 \mu \mathrm{g} / \mathrm{kg}$, IP.) and ketamine hydrochloride (Ketamine, $50 \mathrm{mg} / \mathrm{kg}$, IP.). Carotid arteries were cannulated and connected to Model SMUP-E4 Bioelectric Signals Processing System (MFLab301) to display rat real time heart rates and blood pressure, which were recorded every 1 h.DATS@MIONPEG-LF $(10 \mathrm{mg} / \mathrm{kg})$ or same volume of saline (Sham) was administrated by tail vein injection. Then change of blood pressure and heart rates was evaluated.

\section{Heart/Brain targeting assessment of DATS@MION-PEG-LF}

DiR was loaded to the MION-PEG-LF and MION frameworks. The protocols of loading and the identification of DiR@MION-PEG-LF and DiR@MION were described in the Additional file 1. Immunofluorescence method was applied to study the in vivo targeting ability of DATS@ MION-PEG-LF to brain and heart. Sprague-Dawley rats were injected with either DiR@MION-PEG-LF (10 mg/ $\mathrm{kg}$ ) or DiR@MION (10 mg/kg) by tail vein. At $24 \mathrm{~h}$ after injection, rats were anaesthetized and sacrificed to obtain the brain and heart tissues. The brain and heart tissues were dewaxed and hydrated in dimethylbenzene and a graded series of alcohol, frozen and embedded in Tissuetek O.C.T., and sliced $(10 \mu \mathrm{m})$. Cardiomyocytes cytoplasm were stained with wheat germ agglutinin (WGA, 1:100), neuron cytomembranes were stained with neurofilament protein NF200 (1:100) and goat anti-mouse IgG (1:200), and DAPI was used for labeling of nuclei. The slides were then mounted with an antifade medium and observed with a DMI 4000 fluorescence microscope (Leica Camera Co., Wetzlar, Germany) (detailed in Additional file 1).

\section{In vivo $\mathrm{H}_{2} \mathrm{~S}$ release of DATS@MION-PEG-LF}

Sprague-Dawley rats were anesthetized with medetomidine hydrochloride $(250 \mu \mathrm{g} / \mathrm{kg}$, I.P. $)$ and ketamine hydrochloride $(50 \mathrm{mg} / \mathrm{kg}$, I.P.) $(\mathrm{n}=6)$. Carotid arteries were cannulated for blood withdrawal. 5,10 or $20 \mathrm{mg} /$ kg of DATS@MION-PEG-LF were separately administrated by tail vein injection. Blood $(0.1 \mathrm{~mL})$ was withdrawn at time intervals $(0-12 \mathrm{~h})$ after administration. The blood collected was anticoagulated with heparin sodium $(50 \mathrm{U} / \mathrm{mL})$ and centrifuged $(3000 \mathrm{rpm}, 15 \mathrm{~min})$ to obtain plasma. As to the $\mathrm{H}_{2} \mathrm{~S}$ concentration of DATS@ MION-PEG-LF in plasma cannot be assessed by real time $\mathrm{H}_{2} \mathrm{~S}$-selective microelectrode assay, therefore it was measured by HPLC method by an Agilent Technologies HPLC (1260 infinity, CA, USA) with fluorescence detection ( $\lambda$ ex: $390 \mathrm{~nm}$ and $\lambda \mathrm{em}: 475 \mathrm{~nm}$ ) and an Eclipse XDBC18 column $(150 \cdot 4.6 \mathrm{~mm}, 5 \mu \mathrm{m})$ within $24 \mathrm{~h}$, which was previously described $[7,29]$.

Repeat the experiments, and Sprague-Dawley rats $(\mathrm{n}=6)$ administrated by DATS@MION-PEG-LF (10 mg/ $\mathrm{kg}$ ) or same volume of saline (Vehicle group) were sacrificed at $24 \mathrm{~h}$ after injection. Myocardium and cortices tissues were quickly acquired and stored at $-80^{\circ} \mathrm{C}$. Then small pieces of tissues (about $50 \mathrm{mg}$ ) were homogenated in $500 \mu \mathrm{L}$ of PBS ( $\mathrm{pH} 7.4) . \mathrm{H}_{2} \mathrm{~S}$ concentration of the homogenate was determined by HPLC analysis described above. The protein content of tissue was measured by the bicinchoninic acid (BCA) method using a BCA Protein Assay Kit (Pierce, IL, USA). The $\mathrm{H}_{2} \mathrm{~S}$ content of samples were quantified by protein content.

\section{Rat CA/CPR model}

Sprague-Dawley rats were anesthetized and heparinized $(0.2 \mathrm{~mL}$, I.P.). Then the CA/CPR rat model was established by the previous method [30] (described in Additional file 1). Rats were randomized into three groups: (1) sham $(n=6)$, which were subjected to the same procedure as the other groups except for CA/CPR; (2) Control group $(n=6)$, which underwent $5 \mathrm{~min}$ of $\mathrm{CA}$ and received injection of same volume of saline; (3) DATS@MIONPEG-LF group $(n=6)$, which underwent 5 min of CA and received injection of DATS@MION-PEG-LF (10 mg/kg). 
Drugs were immediately injected after successful resuscitation. At $24 \mathrm{~h}$ after reperfusion, the myocardium and cortices tissues were quickly acquired and stored for subsequent experimental analysis.

\section{Quantitative assessment of neutrophil accumulation}

Heart and brain tissues were assessed for the myeloperoxidase (MPO) activity as a marker of neutrophil accumulation. Tissues were homogenized in a solution containing $0.5 \%$ hexadecyltrimethylammonium bromide dissolved in $10 \mathrm{mM} \mathrm{K} \mathrm{PO}_{4}$ buffer ( $\mathrm{pH}$ 7.0) and centrifuged for $30 \mathrm{~min}\left(20,000 \mathrm{~g}, 4^{\circ} \mathrm{C}\right)$. Supernatant was allowed to react with tetramethylbenzidine $(1.6 \mathrm{mM})$ and $0.1 \mathrm{mM} \mathrm{H}_{2} \mathrm{O}_{2}$, and the change in absorbance was measured by spectrophotometry at $650 \mathrm{~nm}$. The MPO activity was defined as the quantity of enzyme degrading $1 \mathrm{mmol}$ of hydrogen peroxide per min at $37{ }^{\circ} \mathrm{C}$ and expressed in milliunits per milligram protein.

\section{Antioxidant enzyme activities}

A total of $50 \mathrm{mg}$ heart or brain tissue was homogenized in a $50 \mathrm{mM}$ ice-cold potassium phosphate buffer $(\mathrm{pH}$ 6.8). Superoxide dismutase (SOD) activity, catalase (CAT) activity and the malonydialdehyde (MDA) levels were determined by the previously reported method [8]. The activity of SOD and CAT, and the levels of MDA were all standardized by protein content, determined using a bicinchoninic acid (BCA) protein assay kit (Beytime Institute of Biotechnology, Nantong, China).

\section{Transferase-mediated dUTP nick-end labeling (TUNEL) assay}

Acquired heart and brain tissues were stained with $H \& E$, followed by a TUNEL assay: the cell nuclei were stained with $4^{\prime}, 6^{\prime}$-diamidino-2-phenylindole hydrochloride (DAPI) color development kits (Roche, Basil, $\mathrm{CH}$ ) in accordance with the manufacturers' instructions. The cell nuclei that stained green were defined as TUNELpositive nuclei and were monitored using a Nikon invert fluorescence microscope. The proportion of TUNEL positive nuclei per 500 nuclei was quantified at a 200 . magnification.

\section{Western blot assay}

A piece of ischemic brain or heart tissue was homogenized by a rotor-stator homogenizer in ice-cold RIPA buffer (Pierce, Pittsburgh, PA, USA), and incubated at $4{ }^{\circ} \mathrm{C}$ overnight. After boiling with loading buffer (Fermentas, Glen Burnie, MD, USA), denatured proteins were separated in SDS PAGE gel, and transferred onto PVDF membrane. The membrane was blocked with $5 \%$ nonfat milk, followed by incubation with primary antibody of Bcl-2, BAX and Caspase-3 (Abcam, Cambridge,
MA, USA) at $4{ }^{\circ} \mathrm{C}$ overnight. HRP-conjugated secondary antibody (Kangchen Bio-tech, Beijing, China) was used to incubate the membrane for another $2 \mathrm{~h}$. SuperSignal West Pico Chemiluminescent Substrate (Pierce, Pittsburgh, PA, USA) was poured on the membrane to develop the band captured by FluorChem Image System (Alpha Innotech, Santa Clara, CA, USA).

\section{Evaluation of heart and cerebral function}

Repeated CA/CPR protocol $(n=6)$, and cardiac and cerebral function were evaluated at $24 \mathrm{~h}$ after CPR and drug injection. Cerebral function was evaluated by neurological deficit scale (NDS) and balance beam test as to the previous methods [31, 32]. After which, rats were anesthetized for transthoracic echocardiography assessment using the Philips IE 33 system and a 12-4 MHz linear transducer (S12-4, Philips, AMS, NED). Stroke volume, ejection fraction (EF) and fractional shortening (FS) were derived to evaluate cardiac function, which were performed by skilled observer blindly. Repeated the CA/ CPR protocols and kept the rats for 30 days, and survival of the rats were compared between the DATS@MIONPEG-LF and Vehicle groups $(n=30)$.

\section{Statistical analysis}

All statistics were performed using SPSS Statistics Base 17.0 for Windows. Continuous data were expressed as mean \pm standard errors (SEM). One-way analysis of variance (ANOVA) was used to examine statistical comparisons between groups. The significant difference between two groups was analyzed by Student's t test. Survival condition was analyzed using the Kaplan-Meier method. A value of $\mathrm{P}<0.05$ was considered to be significant. All authors had full access to, and take full responsibility for the integrity of the data.

\section{Supplementary Information}

The online version contains supplementary material available at https://doi. org/10.1186/s12951-021-00784-w.

Additional file 1. Additional information

\section{Acknowledgements}

Not applicable.

\section{Authors' contributions}

XS: conceptualization, methodology. YW: writing-original draft preparation. SW: data curation. $\mathrm{KH}$ : visualization. JH: validation. XC: software. FW: supervision. LP: writing-reviewing and editing. All authors read and approved the final manuscript.

\section{Funding}

This work was supported by the National Natural Science Foundation of China $(81601663,81772042)$, Shanghai Shen Kang Clinical Research Cultivation Project (SHDC12018 × 18), Natural Science Foundation of Shanghai 
(19ZR1407300), and Training Funding Program for Shanghai Yiyuan New Star and Youth Medical Talent.

\section{Availability of data and materials}

All data generated or analyzed during this study are included in this published article.

\section{Ethics approval and consent to participate}

Not applicable.

\section{Consent for publication}

All authors agree to be published.

\section{Competing interests}

The authors declare that they have no competing interests.

Received: 25 September 2020 Accepted: 27 January 2021

Published online: 06 February 2021

\section{References}

1. Callans DJ. Out-of-hospital cardiac arrest-the solution is shocking. N Engl J Med. 2019. https://doi.org/10.1056/NEJMp048174.

2. Alan S, Go D, Mozaffarian VL, Roger EJ, Benjamin JD, Berry MJ, Blaha, et al. Heart disease and stroke statistics-2014 update: a report from the American Heart Association. Circulation. 2014; e28-92.

3. Albert CM, Chae CU, Grodstein F, Rose LM, Rexrode KM, Ruskin JN, et al. Prospective study of sudden cardiac death among women in the United States. Circulation. 2003. https://doi.org/10.1161/01.CIR.0000065223 .21530 .11

4. Silverman MG, Scirica BM. Cardiac arrest and therapeutic hypothermia. Trends Cardiovasc Med. 2016. https://doi.org/10.1016/j.tcm.2015.10.002

5. Vandiver M, Snyder SH. Hydrogen sulfide: a gasotransmitter of clinical relevance. J Mol Med (Berl). 2012. https://doi.org/10.1007/s0010 9-012-0873-4.

6. Powell $C R$, Dillon KM, Matson JB. A review of hydrogen sulfide $(H(2)$ S) donors: chemistry and potential therapeutic applications. Biochem Pharmacol. 2018. https://doi.org/10.1016/j.bcp.2017.11.014.

7. Sun X, Wang W, Dai J, Huang J, Shi M, Chu X, et al. Donor heart preservation with a novel long-term and slow-releasing hydrogen sulfide system. Nitric Oxide. 2018. https://doi.org/10.1016/j.niox.2018.09.001.

8. Sun X, Wang W, Dai J, Jin S, Huang J, Guo C, et al. A long-term and slowreleasing hydrogen sulfide donor protects against myocardial ischemia/ reperfusion injury. Sci Rep. 2017. https://doi.org/10.1038/s41598-01703941-0.

9. Li L, Whiteman M, Guan YY, Neo KL, Cheng Y, Lee SW, et al. Characterization of a novel, water-soluble hydrogen sulfide-releasing molecule (GYY4137): new insights into the biology of hydrogen sulfide. Circulation. 2008. https://doi.org/10.1161/CIRCULATIONAHA.107.753467.

10. Xiaotian S, Kong B, Wang W, Chandran P, Selomulya C, Zhang H, et al. Mesoporous silica nanoparticles for glutathione-triggered long-range and stable release of hydrogen sulfide. J Mater Chem B. 2015. https://doi. org/10.1039/c5tb00354g.

11. Bharti C, Nagaich U, Pal AK, Gulati N. Mesoporous silica nanoparticles in target drug delivery system: A review. Int J Pharm Investig. 2015. https:// doi.org/10.4103/2230-973X.160844.

12. Wang W, Liu H, Lu Y, Wang X, Zhang B, Cong S, et al. Controlled-releasing hydrogen sulfide donor based on dual-modal iron oxide nanoparticles protects myocardial tissue from ischemia-reperfusion injury. Int J Nanomed. 2019. https://doi.org/10.2147/IJN.S186225.

13. Chen $L, W u Y$, Wu H, Li J, Xie J, Zang F, et al. Magnetic targeting combined with active targeting of dual-ligand iron oxide nanoprobes to promote the penetration depth in tumors for effective magnetic resonance imaging and hyperthermia. Acta Biomater. 2019. https://doi.org/10.1016/j. actbio.2019.07.017.

14. Geurts M, et al. Therapeutic hypothermia and the risk of infection: a systematic review and meta-analysis. Crit Care Med. 2014;42:231-42.

15. Raynal I, Prigent P, Peyramaure S, Najid A, Rebuzzi C, Corot C. Macrophage endocytosis of superparamagnetic iron oxide nanoparticles: mechanisms and comparison of ferumoxides and ferumoxtran-10. Invest Radiol. 2004. https://doi.org/10.1097/01.rli.0000101027.57021.28.

16. Semelka RC, Helmberger TK. Contrast agents for MR imaging of the liver. Radiology. 2001. https://doi.org/10.1148/radiology.218.1.r01ja2427.

17. Huang G, Zhang C, Li S, Khemtong C, Yang S-G, Tian R, et al. A Nove Strategy for Surface Modification of Superparamagnetic Iron Oxide Nanoparticles for Lung Cancer Imaging. J Mater Chem. 2009. https://doi. org/10.1039/b902358e.

18. Banerjee SS, Aher N, Patil R, Khandare J. Poly(ethylene glycol)prodrug conjugates: concept, design, and applications. J Drug Deliv. 2012;2012:103973.

19. Huang R, Ke W, Han L, Liu Y, Shao K, Ye L, et al. Brain-targeting mechanisms of lactoferrin-modified DNA-loaded nanoparticles I Cereb Blood Flow Metab. 2009. https://doi.org/10.1038/jcbfm.2009.104.

20. Hu K, Shi Y, Jiang W, Han J, Huang S, Jiang X. Lactoferrin conjugated PEG-PLGA nanoparticles for brain delivery: preparation, characterization and efficacy in Parkinson's disease. Int J Pharm. 2011. https://doi. org/10.1016/j.jpharm.2011.05.062.

21. Dauber IM, VanBenthuysen KM, McMurtry IF, Wheeler GS, Lesnefsky EJ, Horwitz LD, Weil JV. Functional coronary microvascular injury evident as increased permeability due to brief ischemia and reperfusion. Circ Res. 1990. https://doi.org/10.1161/01.res.66.4.986.

22. Paulis LE, Geelen T, Kuhlmann MT, Coolen BF, Schäfers M, Nicolay K, et al. Distribution of lipid-based nanoparticles to infarcted myocardium with potential application for MRI-monitored drug delivery. J Control Release. 2012. https://doi.org/10.1016/j.jconrel.2012.06.035.

23. Sodha NR, Clements RT, Feng J, Liu Y, Bianchi C, Horvath EM, et al. The effects of therapeutic sulfide on myocardial apoptosis in response to ischemia-reperfusion injury. Eur J Cardiothorac Surg. 2008. https://doi. org/10.1016/j.ejcts.2008.01.047.

24. Wang W, Sun X, Zhang H, Yang C, Liu Y, Yang W, et al. Controlled release hydrogen sulfide delivery system based on mesoporous silica nanoparticles protects graft endothelium from ischemia-reperfusion injury. Int J Nanomed. 2016. https://doi.org/10.2147/IJN.S104604.

25. Corine C, Visser L, Heleen Voorwinden LR, Harders M, Eloualid L, van Bloois, Daan JA, Crommelin, et al. Coupling of metal containing homing devices to liposomes via a maleimide linker: use of TCEP to stabilize thiolgroups without scavenging metals. J Drug Target. 2004. doi:https://doi. org/10.1080/10611860400010689.569- 73.

26. Katebi S, Esmaeili A, Ghaedi K, Zarrabi A. Superparamagnetic iron oxide nanoparticles combined with NGF and quercetin promote neuronal branching morphogenesis of PC12 cells. Int J Nanomed. 2019. https:// doi.org/10.2147/IJN.S191878.

27. Jiang L, Zhong J, Dou X, Cheng C, Huang Z, Sun X. Effects of ApoE on intracellular calcium levels and apoptosis of neurons after mechanical injury. Neuroscience. 2015. https://doi.org/10.1016/j.neuroscien ce.2015.06.005

28. Kiessling F, Mertens ME, Grimm J, Lammers T. Nanoparticles for imaging: top or flop? Radiology. 2014. https://doi.org/10.1148/radiol.14131520.

29. Tan B, Jin S, Sun J, Gu Z, Zhu X, Sun Y, et al. New method for quantification of gasotransmitter hydrogen sulfide in biological matrices by LC-MS/MS. Sci Rep. 2017. https://doi.org/10.1038/srep46278.

30. Qin S, Chen M-H, Fang W, Tan X-F, Lu X, Yang Y-G, et al. Cerebral protection of epigallocatechin gallate (EGCG) via preservation of mitochondrial function and ERK inhibition in a rat resuscitation model. Drug Des Devel Ther. 2019. https://doi.org/10.2147/DDDT.S215358.

31. Jia X, Koenig MA, Shin H-C, Zhen G, Pardo CA, Hanley DF, et al. Improving neurological outcomes post-cardiac arrest in a rat model: immediate hypothermia and quantitative EEG monitoring. Resuscitation. 2008. https ://doi.org/10.1016/j.resuscitation.2007.08.014.

32. Hausser N, Johnson K, Parsley MA, Guptarak J, Spratt H, Sell SL. Detecting behavioral deficits in rats after traumatic brain injury. JVis Exp. 2018. https ://doi.org/10.3791/56044.

\section{Publisher's note}

Springer Nature remains neutral with regard to jurisdictional claims in published maps and institutional affiliations. 